\title{
USO DE MECANISMO DINÂMICO E INTERATIVO NO ENSINO DE QUÍMICA: UM RELATO DE SALA DE AULA
}

\author{
A. L. M. CAMELO ${ }^{1,2^{*}}$, S. E. MAZZETTO ${ }^{2}$, P. H. M. VASCONCELOS ${ }^{1}$ \\ ${ }^{1}$ Instituto Federal de Educação, Ciência e Tecnologia do Ceará \\ ${ }^{2}$ Universidade Federal do Ceará - Departamento de Química Orgânica e Inorgânica \\ andreluiz0502@yahoo.com.br*
}

Artigo submetido em março /2015 e aceito em março /2016

DOI: 10.15628/holos.2016.2817

\section{RESUMO}

Nos dias atuais é comum observar alunos desmotivados e com pouco interesse em aprender o que é ministrado pelo professor. Cabe ao docente buscar estratégias que venham contribuir de maneira significativa no processo de ensino e aprendizagem do aluno. Sabe-se que a brincadeira é uma característica da criança, porém permanece viva em cada nível de vida de uma pessoa. Seja um brinquedo simples como dominó, até mesmo brincadeiras virtuais, como jogos de vídeo game, comuns para crianças, jovens e adultos. O brincar traz ao ser humano o sentimento de prazer e emoção, desta forma, torna-se uma ferramenta útil para alunos e professores quando se associa aos conceitos teóricos da sala de aula. Com esse contexto, o presente trabalho aborda o assunto de Ligação Química de uma maneira dinâmica e atraente, utilizando o lúdico como ferramenta na sala de aula.

PALAVRAS-CHAVE: Motivação, Lúdico, Ligação Química.

\section{USE OF DYNAMIC AND INTERACTIVE MECHANISM IN CHEMICAL TEACHING: A REPORT OF CLASSROOM EXPERIENCE}

\begin{abstract}
Nowadays, it is common to observe unmotivated students with little interest in learning what is taught by the teacher. It is up to the educator to develop strategies that aim to contribute significantly to both teaching and student learning processes. We know that the game is inherent in childhood, but it remains alive in each stage of a person's life. This experience takes place from simple toys, such as dominoes to virtual video games, they are
\end{abstract}

all common to children, young teens and adults. The act of playing brings to the human being feelings of pleasure and excitement, thus, becoming a useful tool for students and teachers when combining theoretical concepts learned in the classroom. In this context, this paper addresses the topic of Chemical Bonding from a dynamic and attractive approach by using games and playing as tools in the classroom.

KEYWORDS: Motivation, Playful, Chemical Bonding. 


\section{INTRODUÇÃO}

Atualmente, novas metodologias têm sido desenvolvidas para o ensino em sala de aula. Estratégias modernas e simples, utilizando laboratórios, recursos multimídias e outros métodos didáticos são utilizados para dinamizar o processo de aprendizagem em várias áreas do conhecimento, inclusive na Química (BENEDETTI FILHO et al., 2009; SOARES et al., 2003; NETO et al., 2013; FOCETOLA et al., 2012).

No caso desta disciplina que é tão importante em nossa sociedade, são utilizados fundamentos abstratos para explicar fenômenos naturais, tornando-a muitas vezes uma matéria enfadonha para o ensino médio, onde acaba causando pouco ou nenhum interesse nos estudantes e a falta de concentração dos alunos (LIMA e MARCONDES, 2011).

Uma das estratégias para facilitar a aprendizagem é a utilização de exemplos e experimentos que possam minimizar o imaginável, tornando-o mais real possível, pois segundo Giordan (GIORDAN, 1999) a experimentação desperta um forte interesse entre alunos de diversos níveis de escolarização.

No entanto, muitas vezes, os conhecimentos Químicos ainda são tratados nas escolas de uma maneira muito formal, exigindo-se que o aluno memorize fatos, nomes, regras e leis. Outro aspecto importante para a eficiência do ensino de Química é o envolvimento do aluno na construção do seu próprio conhecimento na atividade desenvolvida pelo professor. Sabe-se que não existe uma fórmula exata para se atingir um ensino de qualidade, porém cabe aos educadores utilizar recursos que ativem a capacidade dos alunos para que eles descubram um modo mais simples e eficiente de aprender. Dentre os recursos disponíveis, encontram-se as atividades lúdicas que, quando somadas à educação, tornam-se uma combinação indispensável na melhoria da qualidade de vida das pessoas, pois o lúdico carrega a magia do encantamento, que traz ao aluno os sentimentos de satisfação e prazer (SANTOS ORG, 2010).

São muitos os meios de comunicação onde se podem encontrar trabalhos voltados para a educação em Química, por exemplo, internet, revistas, livros, periódicos, etc. Porém, poucos resultados que envolvem prazer e diversão na função educativa estão disponíveis na literatura, quando se usa as disciplinas de ciências exatas (BENEDETTI FILHO et al., 2009,). Dentro desse contexto, a busca por atividade lúdica proporciona ao professor uma ferramenta importante para o ensino de Química, pois é na sala de aula que acontecem os encontros, a troca de experiência e as interações entre os alunos e o professor (FOCETOLA et al., 2012). Dessa forma, o professor pode utilizar como estratégia a identificação de dificuldade enfrentada pelos discentes, principalmente quanto aos problemas de interpretação de conceitos e definições.

A palavra lúdico vem do latim ludus e significa brincar. Brincadeiras, jogos e dinâmicas são bons exemplos de atividades lúdicas e estão presente na vida das pessoas desde a infância, e permanecem ativas até mesmo na velhice. Cada indivíduo possui uma definição própria, mas o brincar está relacionado ao sentimento da emoção e pode-se afirmar que é algo espontâneo e natural de cada pessoa (SANTOS ORG, 2010).

Além disso, a ludicidade é uma necessidade do ser humano em qualquer idade e não pode ser vista apenas como diversão (FOCETOLA et al., 2012). O desenvolvimento do aspecto lúdico facilita a aprendizagem, o desenvolvimento pessoal, social e cultural; colabora para uma boa saúde 
mental; prepara para um estado interior fértil; facilita os processos de socialização, comunicação, expressão e construção do conhecimento (SANTOS ORG, 2010).

A brincadeira quando bem utilizada torna-se uma ferramenta de alegria, diversão e entretenimento, que ao ser aplicado na escola promove algo diferenciado do tradicional e ajuda o aluno a ter uma nova visão da instituição de ensino, fazendo com que o discente sinta-se motivado a aprender de maneira descontraída. Sendo assim, as brincadeiras e dinâmicas, quando associadas ao ensino, tornam-se ferramentas importantes para a criação de um ambiente criativo e inovador.

\section{METODOLOGIA}

Com o objetivo de dinamizar o processo de ensino e aprendizagem em Química, confeccionaram-se vários crachás informativos dos elementos da tabela periódica com o auxílio dos softwares ChemSketch e PowerPoint. Cada crachá informa acerca da importância de cada elemento, bem como a abundância e a presença deles no cotidiano do aluno. Além disso, utilizaram-se imagens ilustrativas e informações básicas como número atômico, massa molecular e distribuição eletrônica. Alguns dos crachás confeccionados podem ser visualizados na Figura 1.

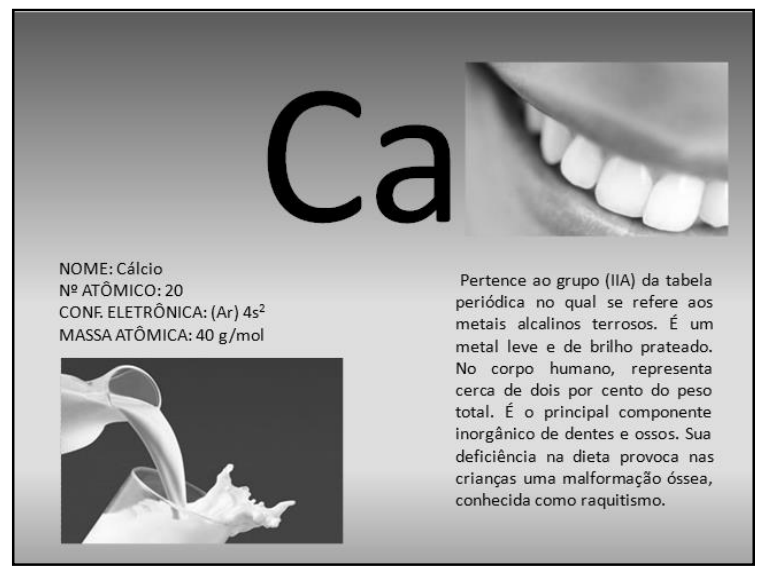

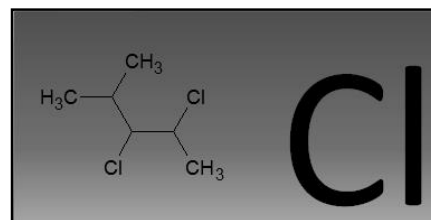

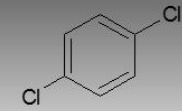

NOME: Cloro № ATÔMICO: 17 CONF. ELETRÔN.: (Ne) $3 \mathrm{~s}^{2} 3 \mathrm{p}^{5}$ MASSA ATÔMICA: $35,5 \mathrm{~g} / \mathrm{mol}$ Pertence ao grupo (VIIA) da tabela
periódica, no qual se refere aos halogênios, é um ametal, de cor amarelo esverdeado $e$ odor sufocante. À temperatura e pressão ambiente, é um gás, que se aspirado em morte. Foi utilizado no $1^{\circ}$ guerra asundia como arma químico É usado no branqueamento do papele desinfetante.
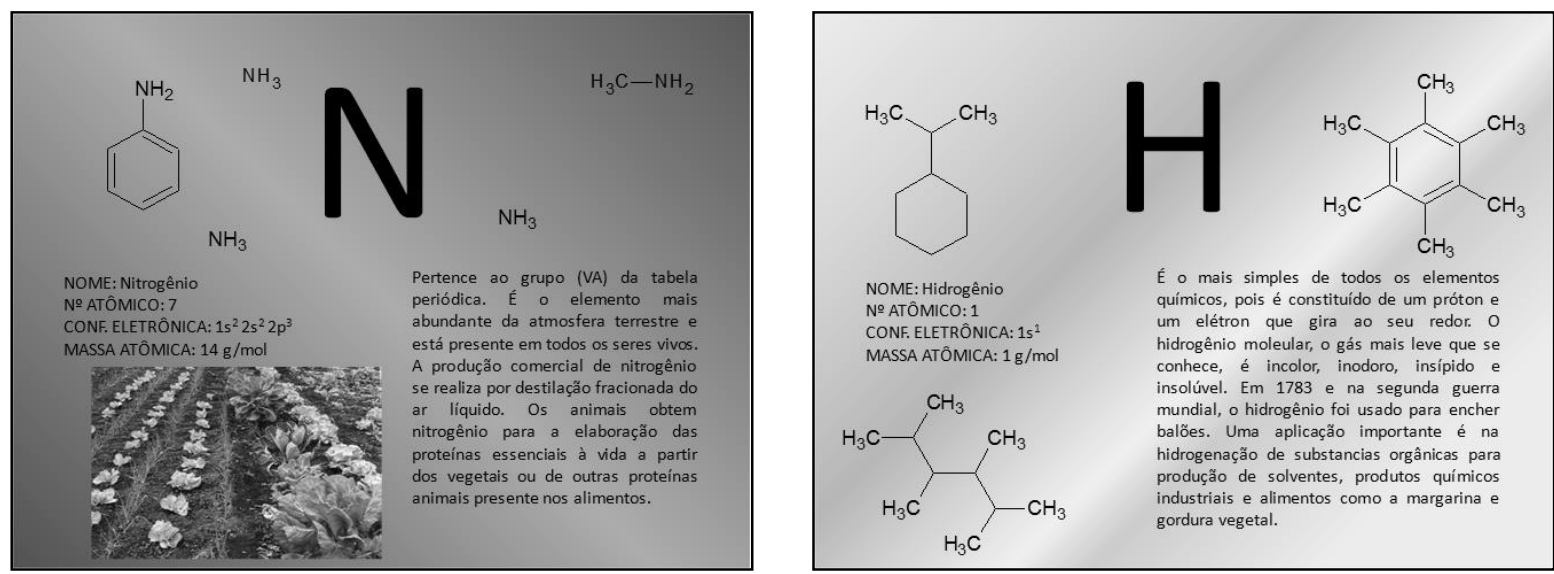

Figura 1 - Crachás confeccionados para a dinâmica.

Realizou-se uma visita a uma escola de ensino médio da rede pública do estado do Ceará. $\mathrm{Na}$ oportunidade, uma conversa com alguns professores de Química foi proposta para apresentar o projeto da atividade lúdica e também para receber possíveis sugestões dos docentes da escola. 
Após conversas e autorização concedida pela direção da escola, realizou-se o primeiro contato com a turma do $1^{\circ}$ ano do ensino médio, composta por vinte e sete alunos.

Na ocasião, realizaram-se os cumprimentos iniciais, estabelecendo um clima descontraído para um melhor conhecimento do grupo. Nessa fase, todas as informações pertinentes ao que seria desenvolvido foram comentadas, como formas de participação, objetivos, conteúdos, além do incentivo a exposição de ideias por parte dos alunos. Assim sendo, iniciou-se na sala de aula o trabalho com conceitos de Ligação Química, explicando porque os átomos ligam-se e as formas possíveis que os elementos usam para interagir uns com os outros.

Com o objetivo de fugir da forma tradicional de educação, desenvolveu-se a dinâmica "Em busca da estabilidade", que aborda os fundamentos de Ligação Química. Desta forma, o aluno deveria utilizar os conceitos básicos e teóricos ministrados anteriormente pelo professor acerca do assunto. Inicialmente, cada aluno presente na sala de aula recebeu um crachá (Figura 1) contendo informações de um elemento Químico. Na ocasião, foi oferecido um tempo para que o participante da dinâmica percorresse a sala de aula e interagisse com os demais colegas, a fim de buscar um parceiro que também interpretava um elemento Químico, no sentido de formar uma ligação Química estável. No final da dinâmica, cada aluno apresentou para os demais colegas da sala de aula o elemento Químico que estava representando, discutiram-se os pontos positivos e negativos da dinâmica e quem se ligou com quem e que tipo de ligação foi formada entre cada aluno.

\section{RESULTADOS E DISCUSSÕES}

Na dinâmica "Em busca da estabilidade", realizada na sala de aula, observou-se que muitos alunos sentiram-se motivados em participar da atividade e aprender as regras da dinâmica, que tinha como fundamentos os conceitos de Ligação Química. A alegria e a satisfação dos alunos puderam ser comprovadas do início ao fim da atividade, ou seja, no período que compreende a apresentação pessoal em sala de aula por parte do professor até a despedida no portão da escola. Relatos informais de que uma atividade diferenciada do tradicional oferecido ao discente e a visita de uma pessoa que não está no cotidiano do aluno foram os fatores que contribuíram na compreensão dos conceitos teóricos de Ligação Química, pois o aluno mostrava-se disposto a oferecer minutos de atenção e conhecer o que o professor tinha de novidade a ser mostrado.

Observou-se no decorrer da dinâmica que um grupo em torno de quatro alunos sentiramse confusos na hora de participar da atividade e não se ligaram corretamente como era esperado. Com o objetivo de solucionar o problema, os demais colegas, com espírito solidário e impulsionados pela vontade de jogar, ajudaram de maneira harmoniosa a resolver tal problema.

Considerando esta situação, notou-se que a dinâmica é eficiente em vários aspectos, um deles é que o jogo incentiva a participação do aluno, considerando o mesmo como sujeito ativo do seu conhecimento e que a atividade valoriza a interação do discente com seus colegas e também com o professor, pois era necessário que o aluno dialogasse e interagisse com os demais membros para poder participar, além de contribuir na fixação do conhecimento trabalhado.

Trabalhos encontrados em periódicos comprovam os resultados obtidos e mostram a importância do lúdico da sala de aula (SOARES e CAVALHEIRO, 2006). Outro aspecto importante levado em consideração nos resultados obtidos veio através de conversas informais com os discentes, onde a maioria dos alunos relatou que a dinâmica facilita o entendimento do conceito 
de Ligação Química, pois se torna mais fácil o aluno aprender quando participa diretamente da atividade. Resultado semelhante, ao utilizar atividade lúdica como facilitador da aprendizagem de um assunto de Química, pôde ser comprovado com o trabalho de Soares (SOARES et al., 2003). No caso deste artigo descrito na literatura trabalhou-se com os conceitos de Equilíbrio Químico, que pode servir de referência, pois utiliza o lúdico como processo de ensino na sala de aula.

\section{CONCLUSÃO}

A avaliação da dinâmica associada com o conteúdo teórico de Ligação Química, observada diretamente na sala de aula e através de relatos de alunos participantes, permite afirmar que os objetivos traçados foram cumpridos, isto é, trabalhar o conteúdo teórico de Ligação Química, desenvolver e aplicar uma dinâmica relacionada ao tema para que venha servir de auxílio no processo de ensino/aprendizagem. Dessa forma, conclui-se que a construção de conceitos e a socialização de conhecimentos por parte dos estudantes foram os pontos em destaque deste trabalho. É importante confirmar que a atividade dinâmica, realizada na escola, tornou-se um instrumento motivador e contribuiu para uma melhor relação entre os alunos e o professor. A dinâmica atuou como elemento configurador na relação entre docente, estudante e conteúdo, não sendo considerada apenas como uma atividade extra, desconectada dos assuntos a ser abordados no ano letivo, mas sim, mostrar eficiência na utilização dessa ferramenta quando bem associada ao ensino na sala de aula.

\section{REFERÊNCIAS BIBLIOGRÁFICAS}

1. BENEDETTI FILHO, E.; FIORUCI, A. R.; BENEDETTI, L. P. D. S.; CRAVEIRO, J. A.. Palavras cruzadas como recurso didático no ensino de teoria atômica. Química nova na escola, v. 31, no 2, p. 8895, 2009.

2. FOCETOLA, P. B. M.; CASTRO, P. J.; SOUZA, A. C. J. D.; GRION, L. D. S.; PEDRO, N. C. D. S.; IACK, R. D. S.; ALMEIDA, R. X. D.; OLIVEIRA, A. C. D.; BARROS, C. V. T. D.; VAITSMAN, E.; BRANDÃO, J. B.; GUERRA, A. C. D. O.; SILVA, J. F. M. D. Os jogos educacionais de cartas como estratégia de ensino de Química. Química nova na escola, no 4, p. 248-255, 2012.

3. GIORDAN, M. O papel da experimentação no ensino de ciências. Química nova na escola: experimentação e ensino de ciências. no 10, p. 43-49, 1999.

4. LIMA, V. A. D.; MARCONDES, M. E. R. Saindo também se aprende - O protagonismo como um processo de ensino-aprendizagem de química. Química nova na escola, v. 33, no 2, p. 100-104, 2011.

5. NETO, H. D. S. M.; PINHEIRO, B. C. S.; ROQUE, N. F. Improvisações teatrais no ensino de Química: Interface entre teatro e ciência na sala de aula. Química nova na escola, no 2, p. 100106, 2013.

6. SANTOS (org.), S. M. P. O Lúdico na formação do educador. 8.ed. Petrópolis: Vozes, 2010.

7. SOARES, M. H. F. B.; CAVALHEIRO, E. T. G. O ludo como um jogo para discutir conceitos em termodinâmica. Química nova na escola, no 23, p. 27-31, 2006.

8. SOARES, M. H. F. B.; OKUMURA, F.; CAVALhEIRO, E. T. G. Proposta de um jogo didático para ensino do conceito de equilíbrio químico. Química nova na escola, no 18, p. 13-17, 2003. 